\title{
The incidence, risk factors and predictive nomograms for early death of lung cancer with synchronous brain metastasis: A retrospective study in the SEER database
}

\section{Heng Shen}

Department of neurosurgery, Suizhou Hospital, Hubei University of Medicine

\section{Gang Deng}

Renmin Hospital of Wuhan University

Qianxue Chen ( $\nabla$ chenqx666@whu.edu.cn )

Renmin Hospital of Wuhan University

Jin Qian

Department of neurosurgery, Suizhou Hospital, Hubei University of Medicine

\section{Research Article}

Keywords: brain metastases, nomogram, early death

Posted Date: March 11th, 2021

DOI: https://doi.org/10.21203/rs.3.rs-243893/v1

License: (c) (i) This work is licensed under a Creative Commons Attribution 4.0 International License. Read Full License

Version of Record: A version of this preprint was published at BMC Cancer on July 16th, 2021. See the published version at https://doi.org/10.1186/s12885-021-08490-4. 


\section{Abstract \\ Background}

Patients of lung cancer with synchronous brain metastases (LCBM) have a poor prognosis and die within a short period of time. However, little is known about the early mortality and related factors of LCBM patients.

\section{Methods}

Patients with LCBM diagnosed between 2010 and 2016 were enrolled from the surveillance, epidemiology, and end result (SEER). Significant independent prognostic factors were identified by univariate and multivariate logistic regression analyses. Nomograms of overall and cancer-specific early death were constructed using independent risk factors. The prediction ability and clinical application value of the model was verified by receiver operating characteristic (ROC) and decision curve analyses (DCAs).

\section{Results}

A total of 29902 cases of LCBM patients were enrolled in this study. $44.4 \%$ had early deaths, of which $38.2 \%$ died of lung cancer. Age, race, gender, Gleason grade, histological type, $T$ stage, $\mathrm{N}$ stage, bone metastasis, liver metastasis, surgery, radiotherapy, chemotherapy and marital status were significant independent risk factors of overall and cancer-specific early death and was used to construct the nomogram. The areas under the curve (AUC) of the training group were $0.828(95 \% \mathrm{Cl}: 0.822-0.833)$ and 0.800 (95\% Cl: $0.794-0.806)$ in the model of overall and cancer-specific early death, respectively. The DCA analysis showed that the model had good clinical benefits and utility

\section{Conclusions}

We established a comprehensive nomogram to distinguish early death in lung cancer patients with synchronous brain metastases which may help oncologists develop better treatment strategies, such as clinical trials and hospice care.

\section{Introduction}

Brain metastasis (BM) is the most common malignant tumor of the central nervous system [1,2]. It is reported that the incidence of brain metastasis is 10 times greater than that of primary malignant brain tumors [3]. Brain metastasis progresses quickly with an average survival time of 13 months [4]. Lung cancer is the major primary tumor of brain metastasis which accounts for more than $80 \%$ of BM [5]. 
Currently, there is no reliable treatment for patients of lung cancer with synchronous brain metastasis (LCBM). Surgery is not recommended for patients with intracranial metastases, because it has no significant effect on the long-term prognosis, although the symptoms are temporarily relieved [6]. As medical care improves, more and more patients with lung cancer benefit from it. The treatment mode of lung cancer has gradually evolved into a new treatment concept combining radiotherapy and targeted therapy [7]. With the development of molecular biology, more signal transduction pathways and tumordriving genes have been discovered, and more targeted drugs have been designed to extend the overall survival of patients [8-10]. However, due to the existence of the blood-brain barrier, it is sometimes difficult to achieve the ideal target drug concentration in the cerebrospinal fluid [11]. Therefore, once brain metastases occur, the treatment of lung cancer could still be very poor.

Many patients with LCBM died of intracranial hypertension and tumor-related epilepsy caused by the tumor within a short time after diagnosis [12]. Death within a short period of time after diagnosis is defined as early death. An in-depth understanding of the relationship between tumor-related factors and early death can reveal the cause of early death in high-risk patients, and provide a basis for further active treatment, clinical trial consideration and supportive treatment. However, few studies have focused on the early death of patients with LCBM. At present, little is known about the early mortality and related factors in patients with LCBM. Therefore, clarifying the risk factors for early death of LCBM patients is of great significance to our prognostic evaluation and clinical treatment guidance.

This study took the LCBM patients in Surveillance, Epidemiology, and End Results (SEER) database as the research object to evaluate the incidence of early death of patients and explore the risk factors of early death ( $\leq 3$ months). In addition, we also developed a module with prognostic factors to predict the early death probability of lung cancer patients with synchronous brain metastases.

\section{Methods}

\section{Patients}

The SEER project of the National Cancer Institute provides data on cancer incidence and survival data in the United States, covering $28 \%$ of the population (http://seer.cancer.gov) [13]. For this study, the SEER ${ }^{\star}$ Stat software version 8.3.8 (reference number: 17293-November 2019) was used to extract data from the World Health Organization (WHO) malignant lung and bronchial cancer patients with synchronous brain metastasis from the SEER database (2010-2016). The study cohort included the following International Classification of Tumor Diseases, third edition (ICD-0-3), histological code: large cell carcinoma: 8012, 8014; squamous cell carcinoma:8070, 8071, 8072, 8073, 8074, 8083; adenoma: $8140,8200,8230,8250,8255,8260,8290,8310,8323$; small cell carcinoma: 8041, 8043, 8044, 8045 and ICD-0-3 site code C34.0-34.8. The exclusion criteria are as follows: (1) Patients without histological examination; (2) Patients without complete follow-up; (3) Patients with missing or incomplete information about survival time, survival status, cause of death, or other important characteristics; (4) Patients not primary. In addition to topography and morphology, it also includes clinical information such 
as gender, race, age, TN stage, insurance status, marital status, surgery (Yes, No/Unknown), radiotherapy (Yes, No/Unknown), and chemotherapy (Yes, No/Unknown). Patients diagnosed in 2010-2015 were used to form a training group to develop a nomogram, and patients diagnosed in 2016 were selected as the internal validation group.

28 patients with brain metastases from lung cancer from Renmin Hospital of Wuhan University were included in the study.

This retrospective study of the hospital cohort was approved by the ethics committee of Renmin Hospital of Wuhan University in accordance with the ethical standards approved by the Helsinki declaration.

\section{Statistical analysis}

Categorized data are described by numbers and percentages $(\mathrm{N}, \%)$. Early death, defined as death within 3 months after diagnosis, is the endpoint of interest for this study. Histogram and pie chart were drawn with SPSS25 (IBM Inc., Chicago, IL, USA). Univariate and multivariate logistic regression models were performed using SPSS 25 to determine variables that were significantly related to early death of patients with LCBM. Two-tailed $P$ values less than 0.05 are considered statistically significant. All statistical analysis below is performed using the R programming language and environment (http://www.rproject.org/). The "regplot" software package was used to construct a nomogram of independent factors predicting early death of lung cancer patients with synchronous brain metastases [14]. For calibration, the nomogram predicted probabilities were contrasted with the actual probabilities by bootstrapping with 1000 resamples. The receiver operating characteristic (ROC) curve was used to judge discrimination. The higher the area under the curve (AUC) was, the better the accuracy would be. AUC values vary from 0.5 to 1.0 , where 0.5 represents random chance, and 1.0 represents full compliance. In general, and AUC value greater than 0.7 means a reasonable estimate [15]. Decision curves analysis (DCA) was used to assess the clinical benefit and utility of the model. DCA is one way to evaluate the clinical benefit of alternative models, and is applied to nomograms by quantifying the net benefit under different threshold probabilities. The curves of the treatment plan (representing the highest clinical cost) and no treatment plan (representing no clinical benefit) for all patients are drawn as two references $[16,17]$.

\section{Results}

\section{Demographic and clinical characteristics of lung cancer patients with synchronous brain metastasis}

This study included 29902 patients diagnosed with synchronous brain metastases of lung cancer from 2010 to 2016 in the SEER database (Figure 1). Table 1 listed the demographic and clinicopathological characteristics of patients in the training set $(n=26272)$ and validation set $(n=3630)$. In general, there were slightly more men than women, and most of them were patients over 40 years old. $79.5 \%$ of cases were reported as white and $12.2 \%$ were black. Most cases were classified into lung adenocarcinoma (51.6\%), and SQCC, SCLC and LCLC accounted for $10.6 \%, 17.0 \%$ and $2.3 \%$, respectively. Gleason grade III lung cancer was significantly higher than other grades. Some patients had brain metastases accompanied by liver metastases $(20.7 \%)$ or bone metastases (33.5\%). Very few patients underwent surgery (3.2\%), a 
small number of patients underwent radiotherapy (21.1\%), and about half of the patients underwent chemotherapy (56.1\%). There was no significant difference in composition between the training group and the validation group.

\section{Mortality of early death}

Among all lung cancer patients, $27.5 \%$ of patients had early deaths, and $22.6 \%$ of them were caused by lung cancer (Figure 2A). The early mortality of patients with LCBM is $44.4 \%$, and the early mortality caused by lung cancer was as high as $38.2 \%$ (Figure $2 \mathrm{~B}$ ). The early death of patients with LCBM remained stable between 2010 and 2016 (Figure 3A). The early death rate increased significantly with age, whites were slightly higher than that of other ethnic groups and men were higher than that of women (Figure 3B, C, D).

\section{Identifying independent factors for early death}

Univariate and multivariate logistic regression were used to analyze the risk factors of early death in patients with LCBM in the SEER training group. The results of univariate and multivariate analysis were shown in Table 2 and 3. In univariate analysis, most clinical and pathological characteristics, such as gender, race, age at diagnosis, Gleason grade, histology, T stage, N stage, bone metastasis, liver metastasis, surgery, radiotherapy, chemotherapy and marital status were related to the probability of overall early death. All significant factors were included in the multivariate analysis. Multivariate analysis showed that gender, race, age at diagnosis, Gleason grade, histology, $\mathrm{T}$ stage, $\mathrm{N}$ stage, bone metastasis, liver metastasis, surgery, radiotherapy and chemotherapy were independent risk factors for predicting overall early death in patients with LCBM. The result of cancer-specific early death is consistent with that of overall early death.

\section{Nomogram construction}

Depending on the multivariate logistic regression analysis model, the risk factor prediction nomogram of the SEER cohort was determined. Figure 4A is an example of using a nomogram to predict the survival probability of a given patient. By calculating each variable point, the total number of points can be attached to the probability of overall early death. Total risk point for most patients in this study is between 750 and 930 . Figure 4B showed the predicting nomogram of the probability of cancer-specific early death.

\section{Nomogram validation}

The nomogram showed good prediction efficiency of the probability of early death. The ROC curve used to assess the overall and cancer-specific early death nomogram is shown in Figure 5 . The areas under the curve (AUC) of the training group were 0.828 (Figure $5 \mathrm{~A}$; overall early death, $95 \% \mathrm{Cl}: 0.822-0.833$ ) and 0.800 (Figure 5B; cancer-specific early death, $95 \% \mathrm{Cl}: 0.794-0.806$ ), respectively. And the AUC of the validation group were 0.851 (Figure $5 \mathrm{C}$; overall early death, $95 \% \mathrm{Cl}$ : $0.838-0.864$ ) and 0.813 (Figure 5D; cancer-specific early death, $95 \% \mathrm{Cl}$ : $0.798-0.828)$, respectively. The calibration curve of the two 
nomograms showed that the prediction and observation result in training and validation group were very consistent (Figure 6). In addition, when predicting overall early death and cancer-specific early death from the nomogram, DCAs showed an ideal net benefit for all patients, indicating that the nomogram had good clinical value for predicting the probability of early death (Figure 7). In the hospital cohort, we scored each patient with the nomogram. Only nomogram of cancer-specific early death was used, since the causes of early death of all patients were lung cancer and related factors. When the patients were divided into high score group and low score group, we found that the early mortality in high score group was much higher than that in low score group, and its AUC was as high as 0.719 (Figure 8; 95\% Cl: 0.545-0.892).

\section{Discussion}

Brain metastasis is one of the common causes of death in cancer patients, and lung cancer is the main primary tumor of brain metastases. With the improvement of lung cancer diagnosis and treatment technology and standardization of treatment, the survival time of lung cancer patients has been significantly extended. However, once brain metastases occur, patients often experience intracranial, limb dysfunction, epilepsy and even delirium, which seriously affect the survival of patients [18]. Brain metastatic from lung cancer has grown up to be a major problem in neurosurgery.

The poor prognosis of brain metastatic lung cancer has always been a concern. However, most studies focus on the long-term survival of patients [19-22]. However, the early death of brain metastatic lung cancer has not been explored. The definition of early death varies from study to study and is usually defined as 30 days to 3 months after diagnosis. In this study, early death was defined as 3 months.

The study found that the overall early death rate of lung cancer was $27.5 \%$, and once brain metastasis occurred, the early death rate increased to $44.4 \%$, which indicated that the prognosis of lung cancer patients became extremely poor. Although the prognosis of lung cancer patients has improved in recent years, we found that the early mortality of patients with brain metastases from lung cancer remained stable from 2010 to 2016, which indicates that we need to pay more attention to early death and related factors to reduce the risk of early death. Further study found that age, race, gender, Gleason grade, histological type, T stage, $\mathrm{N}$ stage, bone metastasis, liver metastasis, surgery, radiotherapy, chemotherapy and marital status were independent risk factors for early death of LCBM patients. Previous studies had shown that they had significant impact on the long-term survival of lung cancer patients (except bone metastases to SCLC), while this study shows that they also have an impact on the early death of patients with LCBM [23].

The study of early death has been applied to advanced cancers of other systems and has shown important clinical significance. Song et al. established a nomogram chart to predict the early mortality of uterine sarcoma, which was significantly better than FIGO stage system [24]. Yang et al. established a model to predict the early mortality of stage IV gastric cancer, and the AUC was as high as 0.847 [25]. All these indicated the feasibility and significance of nomograms in predicting the early death rate of tumors. We set up nomograms of overall and cancer-specific early death probability, through the risk factors 
obtained from logistic regression analysis. The nomograms showed good predictive ability and clinical applicability under receiver operating characteristic curve. Internal validation of the nomogram showed that there was a good agreement between the predicted early deaths and the actual early deaths. DCA curves showed that our nomogram has good clinical benefit and practicability in predicting survival rate. It could provide clinicians and patients with a portable decision-making tool for early death screening and clinical decision-making, so as to customize targeted treatment plans After diagnosis with LCBM.

The study has several limitations. First of all, there is no information on molecular pathological indicators in SEER data set, and there are no positive prognostic variables. These variables may be an effective supplement to the existing system, which will be the main part of our future research. In addition, some indicators related to patients' basic information, such as comorbidity rate, were not included in the study. In addition, although external validation is carried out, the amount of data is small, and the model still needs external validation of larger samples to estimate the accuracy. Similarly, due to the limited information provided by SEER platform, many variables, such as specific surgical methods, radiotherapy and chemotherapy regimens, are usually classified as yes or no, which causes some problems for the reliability of our results.

\section{Conclusion}

In conclusion, we established a comprehensive nomogram to distinguish early death in lung cancer patients with synchronous brain metastases. Nomograms may help oncologists develop better treatment strategies, such as clinical trials and hospice care.

\section{Declarations}

\section{Acknowledgements}

We gratefully acknowledge the SEER project organizers as well as all study participants for making data and results available.

\section{Authors' contributions}

JQ and QC designed this study. HS and GD performed the data collection and wrote the paper. QC revised the manuscript.

\section{Funding}

Not applicable.

\section{Availability of data and materials}

The raw data of this study are derived from the SEER database, which is a publicly available database. The SEER detailed data of SEER database included in the study are available to all 
at https://seer.cancer.gov/. The hospital cohort database was available in the supplementary materials. More specific data used during the present study are available from the corresponding author upon reasonable request.

\section{Ethics approval and consent to participate}

This study complied with the Declaration of Helsinki. The analysis dataset will be extracted without any identifiable information. Thus, informed consent has been waived. Ethical approval for use of clinical data of LCBM patients in this study was approved by the Renmin Hospital of Wuhan University's Institutional Ethics Committee of the Faculty of Medicine (approval number: 2012LKSZ (010) H).

\section{Consent for publication}

Not applicable.

\section{Competing interests}

All authors declare that they have no competing interests.

\section{References}

1. Sacks P, Rahman M. Epidemiology of Brain Metastases. Neurosurg Clin N Am. 2020 Oct;31(4):481488. doi: 10.1016/j.nec.2020.06.001.

2. Kotecha R, Gondi V, Ahluwalia MS, Brastianos PK, Mehta MP. Recent advances in managing brain metastasis. F1000Res. 2018 Nov 9;7: F1000 Faculty Rev-1772. doi:

10.12688/f1000research.15903.1.

3. Davis FG, Dolecek TA, McCarthy BJ, Villano JL. Toward determining the lifetime occurrence of metastatic brain tumors estimated from 2007 United States cancer incidence data. Neuro Oncol. 2012 Sep;14(9):1171-7. doi: 10.1093/neuonc/nos152.

4. Kromer C, Xu J, Ostrom QT, Gittleman H, Kruchko C, Sawaya R, Barnholtz-Sloan JS. Estimating the annual frequency of synchronous brain metastasis in the United States 2010-2013: a populationbased study. J Neurooncol. 2017 Aug;134(1):55-64. doi: 10.1007/s11060-017-2516-7.

5. Cagney DN, Martin AM, Catalano PJ, Redig AJ, Lin NU, Lee EQ, Wen PY, Dunn IF, Bi WL, Weiss SE, Haas-Kogan DA, Alexander BM, Aizer AA. Incidence and prognosis of patients with brain metastases at diagnosis of systemic malignancy: a population-based study. Neuro Oncol. 2017 Oct 19;19(11):1511-1521. doi: 10.1093/neuonc/nox077.

6. Consonni D, Pierobon M, Gail MH, Rubagotti M, Rotunno M, Goldstein A, Goldin L, Lubin J, Wacholder S, Caporaso NE, Bertazzi PA, Tucker MA, Pesatori AC, Landi MT. Lung cancer prognosis before and after recurrence in a population-based setting.

7. J Natl Cancer Inst. 2015 Mar 23;107(6): djv059. doi: 10.1093/jnci/djv059. 
8. Naylor EC, Desani JK, Chung PK. Targeted Therapy and Immunotherapy for Lung Cancer. Surg Oncol Clin N Am. 2016 Jul;25(3):601-9. doi: 10.1016/j.soc.2016.02.011.

9. Janakiram M, Pareek V, Cheng H, Narasimhulu DM, Zang X. Immune checkpoint blockade in human cancer therapy: lung cancer and hematologic malignancies. Immunotherapy. 2016 Jun;8(7):809-19. doi: 10.2217/imt-2016-0001.

10. Yong CSM, Dardalhon V, Devaud C, Taylor N, Darcy PK, Kershaw MH. CAR T-cell therapy of solid tumors. Immunol Cell Biol. 2017 Apr;95(4):356-363. doi: 10.1038/icb.2016.128.

11. Tan WL, Jain A, Takano A, Newell EW, lyer NG, Lim WT, Tan EH, Zhai W, Hillmer AM, Tam WL, Tan DSW. Novel therapeutic targets on the horizon for lung cancer.

12. Lancet Oncol. 2016 Aug;17(8): e347-e362. doi: 10.1016/S1470-2045(16)30123-1.

13. Niranjan A, Lunsford LD, Ahluwalia MS. Targeted Therapies for Brain Metastases. Prog Neurol Surg. 2019;34: 125-137. doi: 10.1159/000493057. Epub 2019 May 16.

14. Yamanaka R, Koga H, Yamamoto Y, Yamada S, Sano T, Fukushige T. Characteristics of patients with brain metastases from lung cancer in a palliative care center. Support Care Cancer. 2011 Apr;19(4):467-73. doi: 10.1007/s00520-010-0838-5.

15. Qiu MZ, Shi SM, Chen ZH, Yu HE, Sheng H, Jin Y, Wang DS, Wang FH, Li YH, Xie D, Zhou ZW, Yang DJ, $\mathrm{Xu} \mathrm{RH}$. Frequency and clinicopathological features of metastasis to liver, lung, bone, and brain from gastric cancer: A SEER-based study.

16. Cancer Med. 2018 Aug;7(8):3662-3672. doi: 10.1002/cam4.1661.

17. Zhao Y, Xu G, Guo X, Ma W, Xu Y, Peltzer K, Chekhonin VP, Baklaushev VP, Hu N, Wang X, Liu Z, Zhang C. Early Death Incidence and Prediction in Stage IV Breast Cancer. Med Sci Monit. 2020 Aug 11;26: e924858. doi: 10.12659/MSM.924858.

18. Wu J, Zhang H, Li L, Hu M, Chen L, Xu B, Song Q. A nomogram for predicting overall survival in patients with low-grade endometrial stromal sarcoma: A population-based analysis. Cancer Commun (Lond). 2020 Jul;40(7):301-312. doi: 10.1002/cac2.12067.

19. Fitzgerald M, Saville BR, Lewis RJ. Decision curve analysis. JAMA. 2015;313(4):409-10. DOI: 10.1001/jama.2015.37

20. Vickers AJ, Elkin EB. Decision curve analysis: A novel method for evaluating prediction models. Med Decis Making. 2006;26(6):565 - 74. 27. Camp RL, Dolled-F DOI: 10.1177/0272989X06295361

21. Schmidt-Hansen M, Berendse S, Hamilton W. Symptomatic diagnosis of cancer of the brain and central nervous system in primary care: a systematic review. Fam Pract. 2015 Dec;32(6):618-23. doi: 10.1093/fampra/cmv075.

22. Ascha MS, Ostrom QT, Wright J, Kumthekar P, Bordeaux JS, Sloan AE, Schumacher FR, Kruchko C, Barnholtz-Sloan JS. Lifetime Occurrence of Brain Metastases Arising from Lung, Breast, and Skin Cancers in the Elderly: A SEER-Medicare Study. Cancer Epidemiol Biomarkers Prev. 2019 May;28(5):917-925. doi: 10.1158/1055-9965.EPI-18-1116.

23. Wang M, Wu Q, Zhang J, Qin G, Yang T, Liu Y, Wang X, Zhang B, Wei Y. 
24. Prognostic impacts of extracranial metastasis on non-small cell lung cancer with brain metastasis: A retrospective study based on surveillance, epidemiology, and end results database. Cancer Med. 2020 Dec 15. doi: 10.1002/cam4.3562.

25. Gu Y, Zhang J, Zhou Z, Liu D, Zhu H, Wen J, Xu X, Chen T, Fan M. Metastasis Patterns and Prognosis of Octogenarians with NSCLC: A Population-based Study. Aging Dis. 2020 Feb 1;11(1):82-92. doi: 10.14336/AD.2019.0414.

26. Yang J, Zhang Y, Sun X, Gusdon AM, Song N, Chen L, Jiang G, Huang Y. The prognostic value of multiorgan metastases in patients with non-small cell lung cancer and its variants: a SEER-based study. J Cancer Res Clin Oncol. 2018 Sep;144(9):1835-1842. doi: 10.1007/s00432-018-2702-9.

27. Goncalves PH, Peterson SL, Vigneau FD, Shore RD, Quarshie WO, Islam K, Schwartz AG, Wozniak AJ, Gadgeel SM. Risk of brain metastases in patients with nonmetastatic lung cancer: Analysis of the Metropolitan Detroit Surveillance, Epidemiology, and End Results (SEER) data. Cancer. 2016 Jun 15;122(12):1921-7. doi: 10.1002/cncr.30000.

28. Song Z, Wang Y, Zhang D, Zhou Y. A Novel Tool to Predict Early Death in Uterine Sarcoma Patients: A Surveillance, Epidemiology, and End Results-Based Study.

29. Front Oncol. 2020 Nov 26; 10:608548. doi: 10.3389/fonc.2020.608548.

30. Yang Y, Chen ZJ, Yan S. The incidence, risk factors and predictive nomograms for early death among patients with stage IV gastric cancer: a population-based study.

31. J Gastrointest Oncol. 2020 Oct;11(5):964-982. doi: 10.21037/jgo-20-217.

\section{Tables}

Table 1₫Demographic and tumor characteristics in patients with brain metastases lung cancer. 


\begin{tabular}{|c|c|c|c|c|c|c|}
\hline $\begin{array}{l}\text { Variable } \\
\text { Total }\end{array}$ & All subjects & {$[\operatorname{cases}(\%)]$} & Training set & {$[\operatorname{cases}(\%)]$} & Validation set & [cases (\%)] \\
\hline \multicolumn{7}{|l|}{ Gender } \\
\hline Male & 15596 & 52.2 & 13741 & 52.3 & 1855 & 51.1 \\
\hline Female & 14306 & 47.8 & 12531 & 47.7 & 1775 & 48.9 \\
\hline \multicolumn{7}{|l|}{ Age } \\
\hline$<40$ & 252 & 0.8 & 212 & 0.8 & 40 & 1.1 \\
\hline $40-49$ & 1648 & 5.5 & 1479 & 5.6 & 169 & 4.7 \\
\hline $50-59$ & 7149 & 23.9 & 6308 & 24.0 & 841 & 23.2 \\
\hline $60-69$ & 10447 & 34.9 & 9150 & 34.8 & 1297 & 35.7 \\
\hline $70-79$ & 7751 & 25.9 & 6775 & 25.8 & 976 & 26.9 \\
\hline$>=80$ & 2655 & 8.9 & 2348 & 8.9 & 307 & 8.5 \\
\hline \multicolumn{7}{|l|}{ Race } \\
\hline White & 23759 & 79.5 & 20947 & 79.7 & 2812 & 77.5 \\
\hline Black & 3643 & 12.2 & 3190 & 12.1 & 453 & 12.5 \\
\hline Other & 2500 & 8.4 & 2135 & 8.1 & 365 & 10.1 \\
\hline \multicolumn{7}{|l|}{ Histology } \\
\hline $\mathrm{AD}$ & 15427 & 51.6 & 13467 & 51.3 & 1960 & 54.0 \\
\hline SQCC & 3164 & 10.6 & 2770 & 10.5 & 394 & 10.9 \\
\hline LCLC & 675 & 2.3 & 601 & 2.3 & 74 & 2.0 \\
\hline SCLC & 5087 & 17.0 & 4480 & 17.1 & 607 & 16.7 \\
\hline Other & 5547 & 18.6 & 4952 & 18.8 & 595 & 16.4 \\
\hline \multicolumn{7}{|l|}{ Gleason grade } \\
\hline I & 463 & 1.5 & 409 & 1.6 & 54 & 1.5 \\
\hline II & 2677 & 9.0 & 2398 & 9.1 & 279 & 7.7 \\
\hline III & 7821 & 26.2 & 6927 & 26.4 & 894 & 24.6 \\
\hline IV & 1046 & 3.5 & 954 & 3.6 & 92 & 2.5 \\
\hline Unknown & 17895 & 59.8 & 15584 & 59.3 & 2311 & 63.7 \\
\hline \multicolumn{7}{|l|}{ T Stage } \\
\hline T0 & 292 & 1.0 & 266 & 1.0 & 26 & 0.7 \\
\hline T1 & 3244 & 10.8 & 2803 & 10.7 & 441 & 12.1 \\
\hline $\mathrm{T} 2$ & 7386 & 24.7 & 6441 & 24.5 & 945 & 26.0 \\
\hline T3 & 6534 & 21.9 & 5826 & 22.2 & 708 & 19.5 \\
\hline $\mathrm{T} 4$ & 8802 & 29.4 & 7674 & 29.2 & 1128 & 31.1 \\
\hline $\mathrm{Tx}$ & 3644 & 12.2 & 3262 & 12.4 & 382 & 10.5 \\
\hline \multicolumn{7}{|l|}{ N Stage } \\
\hline No & 6446 & 21.6 & 5675 & 21.6 & 771 & 21.2 \\
\hline N1 & 2531 & 8.5 & 2213 & 8.4 & 318 & 8.8 \\
\hline N2 & 13441 & 45.0 & 11892 & 45.4 & 1549 & 42.7 \\
\hline N3 & 5773 & 19.3 & 4994 & 19.0 & 779 & 21.5 \\
\hline $\mathrm{Nx}$ & 1711 & 5.7 & 1498 & 5.7 & 213 & 5.9 \\
\hline \multicolumn{7}{|l|}{ Bone Met } \\
\hline Yes & 10024 & 33.5 & 8750 & 33.3 & 1274 & 35.1 \\
\hline None & 19306 & 64.6 & 17006 & 64.7 & 2300 & 63.4 \\
\hline Unknown & 572 & 1.9 & 516 & 2.0 & 56 & 1.5 \\
\hline \multicolumn{7}{|l|}{ Liver Met } \\
\hline Yes & 6189 & 20.7 & 5390 & 20.5 & 799 & 22.0 \\
\hline None & 22971 & 76.8 & 20226 & 77.0 & 2745 & 75.6 \\
\hline Unknown & 742 & 2.5 & 656 & 2.5 & 86 & 2.4 \\
\hline \multicolumn{7}{|l|}{ Surgery } \\
\hline Yes & 961 & 3.2 & 858 & 3.3 & 103 & 2.8 \\
\hline None/ Unknown & 28941 & 96.8 & 25414 & 96.7 & 3527 & 97.2 \\
\hline \multicolumn{7}{|l|}{ Chemotherapy } \\
\hline Yes & 16767 & 56.1 & 14762 & 56.2 & 2005 & 55.2 \\
\hline None/ Unknown & 13135 & 43.9 & 11510 & 43.8 & 1625 & 44.8 \\
\hline \multicolumn{7}{|l|}{ Radiotherapy } \\
\hline Yes & 6307 & 21.1 & 5497 & 20.9 & 810 & 22.3 \\
\hline None/ Unknown & 23595 & 78.9 & 20775 & 79.1 & 2820 & 77.7 \\
\hline
\end{tabular}




\begin{tabular}{lllllll} 
Insurance & & & & & \\
Yes & 28191 & 94.3 & 24723 & 94.1 & 3468 & 95.5 \\
\hline None & 1221 & 4.1 & 1128 & 4.3 & 93 & 2.6 \\
Unknown & 490 & 1.6 & 421 & 1.6 & 69 & 1.9 \\
Marital & & & & & & \\
Single & 13326 & 44.6 & 11643 & 44.3 & 1683 & 46.4 \\
Married & 15424 & 51.6 & 13608 & 51.8 & 1816 & 50.0 \\
Unknown & 1152 & 3.9 & 1021 & 3.9 & 131 & 3.6 \\
\hline
\end{tabular}

Table 2₫Univariate logistic regression analysis of the training dataset. 


\begin{tabular}{|c|c|c|c|c|c|c|}
\hline \multirow{2}{*}{ Variable } & \multicolumn{3}{|c|}{ Overall early-death } & \multicolumn{3}{|c|}{ Cancer-specific early-death } \\
\hline & OR & $95 \%$ CI & $\mathrm{P}$ & $\mathrm{OP}$ & $95 \%$ CI & $\mathrm{P}$ \\
\hline \multicolumn{7}{|l|}{ Gender } \\
\hline Male & Ref & & & Ref & & \\
\hline Female & 0.745 & $0.709-0.784$ & $<0.001$ & 0.773 & $0.734-0.815$ & $<0.001$ \\
\hline \multicolumn{7}{|l|}{ Age } \\
\hline$<40$ & Ref & & & Ref & & \\
\hline $40-49$ & 1.57 & $1.046-2.356$ & 0.03 & 1.441 & 0.942-2.205 & 0.092 \\
\hline $50-59$ & 2.43 & $1.645-3.589$ & $<0.001$ & 2.215 & $1.473-3.33$ & $<0.001$ \\
\hline $60-69$ & 3.205 & $2.173-4.727$ & $<0.001$ & 2.921 & $1.946-4.385$ & $<0.001$ \\
\hline $70-79$ & 4.687 & $3.176-6.917$ & $<0.001$ & 4.169 & 2.776 & $<0.001$ \\
\hline$>=80$ & 6.824 & $4.599-10.126$ & $<0.001$ & 5.571 & 3.69-8.411 & $<0.001$ \\
\hline \multicolumn{7}{|l|}{ Race } \\
\hline White & Ref & & & Ref & & \\
\hline Black & 0.907 & $0.839-0.981$ & 0.014 & 0.891 & $0.821-0.966$ & 0.005 \\
\hline Other & 0.695 & $0.630-0.766$ & $<0.001$ & 0.705 & 0.637-0.781 & $<0.001$ \\
\hline \multicolumn{7}{|l|}{ Histology } \\
\hline $\mathrm{AD}$ & Ref & & & & & \\
\hline SQCC & 1.784 & $1.642-1.939$ & $<0.001$ & 1.7 & $1.561-1.85$ & $<0.001$ \\
\hline LCLC & 1.238 & $1.045-1.467$ & 0.014 & 1.228 & $1.031-1.463$ & 0.022 \\
\hline SCLC & 1.192 & $1.111-1.28$ & $<0.001$ & 1.156 & $1.074-1.245$ & $<0.001$ \\
\hline Other & 1.568 & $1.466-1.676$ & $<0.001$ & 1.433 & $1.337-1.535$ & $<0.001$ \\
\hline \multicolumn{7}{|l|}{ Gleason grade } \\
\hline I & Ref & & & Ref & & \\
\hline II & 1.121 & $0.885-1.421$ & 0.344 & 1.17 & $0.912-1.502$ & 0.217 \\
\hline III & 1.814 & $1.448-2.272$ & $<0.001$ & 1.813 & $1.43-2.298$ & $<0.001$ \\
\hline IV & 1.682 & $1.302-2.172$ & $<0.001$ & 1.731 & $1.324-2.264$ & $<0.001$ \\
\hline Unknown & 1.568 & $1.256-1.958$ & $<0.001$ & 1.519 & $1.202-1.921$ & $<0.001$ \\
\hline \multicolumn{7}{|l|}{ T Stage } \\
\hline T0 & Ref & & & Ref & & \\
\hline T1 & 0.96 & $0.722-1.276$ & 0.779 & 1.352 & 0.969-1.886 & 0.076 \\
\hline T2 & 1.315 & 0.997-1.734 & 0.053 & 1.928 & $1.393-2.669$ & $<0.001$ \\
\hline T3 & 1.674 & $1.269-2.207$ & $<0.001$ & 2.384 & $1.722-3.3$ & $<0.001$ \\
\hline $\mathrm{T} 4$ & 1.826 & $1.387-2.406$ & $<0.001$ & 2.648 & 1.915-3.661 & $<0.001$ \\
\hline $\mathrm{Tx}$ & 1.925 & $1.454-2.548$ & $<0.001$ & 2.561 & $1.844-3.557$ & $<0.001$ \\
\hline \multicolumn{7}{|l|}{ N Stage } \\
\hline N0 & Ref & & & Ref & & \\
\hline N1 & 0.93 & $0.838-1.034$ & 0.18 & 0.961 & $0.86-1.072$ & 0.474 \\
\hline N2 & 1.203 & $1.126-1.286$ & $<0.001$ & 1.226 & $1.144-1.315$ & $<0.001$ \\
\hline N3 & 1.154 & $1.065-1.25$ & $<0.001$ & 1.2 & $1.105-1.304$ & $<0.001$ \\
\hline $\mathrm{Nx}$ & 1.553 & $1.383-1.745$ & $<0.001$ & 1.454 & $1.289-1.64$ & $<0.001$ \\
\hline \multicolumn{7}{|l|}{ Bone Met } \\
\hline Yes & Ref & & & Ref & & \\
\hline None & 0.728 & $0.690-0.768$ & $<0.001$ & 0.728 & $0.689-0.769$ & $<0.001$ \\
\hline Unknown & 0.998 & $0.833-1.196$ & 0.984 & 0.903 & $0.748-1.09$ & 0.286 \\
\hline \multicolumn{7}{|l|}{ Liver Met } \\
\hline Yes & Ref & & & Ref & & \\
\hline None & 0.519 & $0.489-0.552$ & $<0.001$ & 0.543 & $0.51-0.577$ & $<0.001$ \\
\hline Unknown & 0.771 & $0.654-0.909$ & 0.002 & 0.796 & $0.673-0.942$ & 0.008 \\
\hline \multicolumn{7}{|l|}{ Surgery } \\
\hline Yes & Ref & & & Ref & & \\
\hline None/ Unknown & 4.069 & $3.320-4.986$ & $<0.001$ & 4.18 & $3.344-5.236$ & $<0.001$ \\
\hline \multicolumn{7}{|c|}{ Chemotherapy } \\
\hline Yes & Ref & & & Ref & & \\
\hline None/ Unknown & 9.908 & $9.339-10.511$ & $<0.001$ & 7.619 & $7.176-8.09$ & $<0.001$ \\
\hline \multicolumn{7}{|l|}{ Radiotherapy } \\
\hline Yes & Ref & & & Ref & & \\
\hline None/ Unknown & 3.311 & $3.072-3.569$ & $<0.001$ & 3.101 & $2.865-3.357$ & $<0.001$ \\
\hline
\end{tabular}




\begin{tabular}{lllllll} 
Insurance & \multicolumn{7}{l}{} \\
Yes & Ref & & & & \\
None & 0.894 & $0.791-1.01$ & 0.073 & 0.947 & $0.834-1.076$ & 0.407 \\
Unknown & 1.156 & $0.920-1.451$ & 0.213 & 1.119 & $0.883-1.417$ & 0.352 \\
\hline Marital & & & & & & \\
Single & Ref & & & Ref & & \\
Married & 0.805 & $0.764-0.847$ & $<0.001$ & 0.824 & $0.781-0.869$ & $<0.001$ \\
\hline Unknown & 0.906 & $0.794-1.035$ & 0.147 & 0.841 & $0.731-0.967$ & 0.015 \\
\hline
\end{tabular}

Table 3. Multivariate logistic regression analysis of the training dataset. 


\begin{tabular}{|c|c|c|c|c|c|c|}
\hline \multirow{2}{*}{$\begin{array}{l}\text { Variable } \\
\text { Gender }\end{array}$} & \multicolumn{3}{|c|}{\begin{tabular}{ccc}
\multicolumn{3}{c}{ Overall early-death } \\
OR & $95 \% \mathrm{CI} \quad \mathrm{P}$ \\
\end{tabular}} & \multicolumn{3}{|c|}{$\begin{array}{c}\text { Cancer-specific early-death } \\
\text { Ch }\end{array}$} \\
\hline & & & & & & \\
\hline Male & Ref & & & Ref & & \\
\hline Female & 0.787 & $0.740-0.838$ & $<0.001$ & 0.828 & $0.779-0.881$ & $<0.001$ \\
\hline \multicolumn{7}{|l|}{ Age } \\
\hline$<40$ & Ref & & & Ref & & $<0.001$ \\
\hline $40-49$ & 1.625 & $1.020-2.588$ & 0.041 & 1.433 & $0.896-2.292$ & 0.134 \\
\hline $50-59$ & 2.042 & $1.306-3.192$ & 0.002 & 1.802 & $1.148-2.827$ & 0.01 \\
\hline $60-69$ & 2.434 & $1.559-3.8$ & $<0.001$ & 2.153 & $1.375-3.372$ & 0.001 \\
\hline $70-79$ & 3.019 & $1.932-4.716$ & $<0.001$ & 2.627 & $1.676-4.117$ & $<0.001$ \\
\hline$>=80$ & 3.105 & $1.975-4.883$ & $<0.001$ & 2.557 & $1.622-4.032$ & $<0.001$ \\
\hline \multicolumn{7}{|l|}{ Race } \\
\hline White & Ref & & & Ref & & \\
\hline Black & 0.803 & $0.730-0.883$ & $<0.001$ & 0.807 & $0.734-0.888$ & $<0.001$ \\
\hline Other & 0.733 & $0.652-0.824$ & $<0.001$ & 0.751 & $0.668-0.844$ & $<0.001$ \\
\hline \multicolumn{7}{|l|}{ Histology } \\
\hline $\mathrm{AD}$ & Ref & & & Ref & & \\
\hline SQCC & 1.441 & $1.302-1.596$ & $<0.001$ & 1.234 & $1.004-1.517$ & 0.045 \\
\hline LCLC & 1.271 & $1.031-1.565$ & 0.025 & 1.161 & $1.071-1.259$ & $<0.001$ \\
\hline SCLC & 1.424 & $1.297-1.563$ & $<0.001$ & 1.313 & $1.197-1.441$ & $<0.001$ \\
\hline Other & 1.287 & $1.185-1.397$ & $<0.001$ & 1.345 & $1.218-1.486$ & $<0.001$ \\
\hline \multicolumn{7}{|c|}{ Gleason grade } \\
\hline & Ref & & & Ref & & \\
\hline II & 1.186 & $0.897-1.568$ & 0.23 & 1.225 & $0.924-1.622$ & 0.158 \\
\hline III & 1.794 & $1.376-2.339$ & $<0.001$ & 1.745 & $1.335-2.28$ & $<0.001$ \\
\hline IV & 1.753 & $1.288-2.385$ & $<0.001$ & 1.771 & $1.301-2.412$ & $<0.001$ \\
\hline Unknown & 1.565 & $1.204-2.035$ & 0.001 & 1.475 & $1.132-1.923$ & 0.004 \\
\hline \multicolumn{7}{|l|}{ T Stage } \\
\hline T0 & Ref & & & Ref & & \\
\hline T1 & 1.051 & $0.759-1.457$ & 0.764 & 1.523 & $1.062-2.185$ & 0.022 \\
\hline T2 & 1.391 & $1.012-1.912$ & 0.042 & 2.079 & $1.461-2.959$ & $<0.001$ \\
\hline T3 & 1.769 & $1.286-2.433$ & $<0.001$ & 2.497 & $1.754-3.555$ & $<0.001$ \\
\hline $\mathrm{T} 4$ & 1.916 & $1.395-2.632$ & $<0.001$ & 2.757 & $1.939-3.92$ & $<0.001$ \\
\hline $\mathrm{Tx}$ & 1.72 & $1.246-2.375$ & 0.001 & 2.326 & $1.628-3.322$ & $<0.001$ \\
\hline \multicolumn{7}{|l|}{ N Stage } \\
\hline No & Ref & & & Ref & & \\
\hline N1 & 1.037 & $0.913-1.178$ & 0.58 & 1.044 & $0.92-1.186$ & 0.501 \\
\hline N2 & 1.367 & $1.259-1.484$ & $<0.001$ & 1.328 & $1.225-1.441$ & $<0.001$ \\
\hline N3 & 1.558 & $1.410-1.721$ & $<0.001$ & 1.51 & $1.368-1.666$ & $<0.001$ \\
\hline $\mathrm{Nx}$ & 1.104 & $0.956-1.274$ & 0.178 & 1.075 & $0.933-1.239$ & 0.317 \\
\hline \multicolumn{7}{|l|}{ Bone Met } \\
\hline Yes & Ref & & & Ref & & \\
\hline None & 0.743 & 0.693-0.796 & $<0.001$ & 0.764 & $0.714-0.818$ & $<0.001$ \\
\hline Unknown & 0.597 & $0.470-0.758$ & $<0.001$ & 0.567 & $0.447-0.719$ & $<0.001$ \\
\hline \multicolumn{7}{|l|}{ Liver Met } \\
\hline Yes & Ref & & & Ref & & \\
\hline None & 0.529 & $0.489-0.573$ & $<0.001$ & 0.582 & $0.54-0.629$ & $<0.001$ \\
\hline Unknown & 0.629 & $0.505-0.783$ & $<0.001$ & 0.75 & $0.605-0.93$ & 0.009 \\
\hline \multicolumn{7}{|l|}{ Surgery } \\
\hline Yes & Ref & & & Ref & & \\
\hline None/ Unknown & 2.182 & $1.723-2.765$ & $<0.001$ & 2.319 & $1.806-2.978$ & $<0.001$ \\
\hline \multicolumn{7}{|l|}{ Chemotherapy } \\
\hline Yes & Ref & & & Ref & & \\
\hline None/ Unknown & 10.915 & $10.211-11.668$ & $<0.001$ & 8 & $7.488-8.546$ & $<0.001$ \\
\hline \multicolumn{7}{|l|}{ Radiotherapy } \\
\hline & & & & Ref & & \\
\hline None/ Unknown & 2.258 & $2.064-2.469$ & $<0.001$ & 2.019 & $1.843-2.211$ & $<0.001$ \\
\hline
\end{tabular}




\section{Figures}

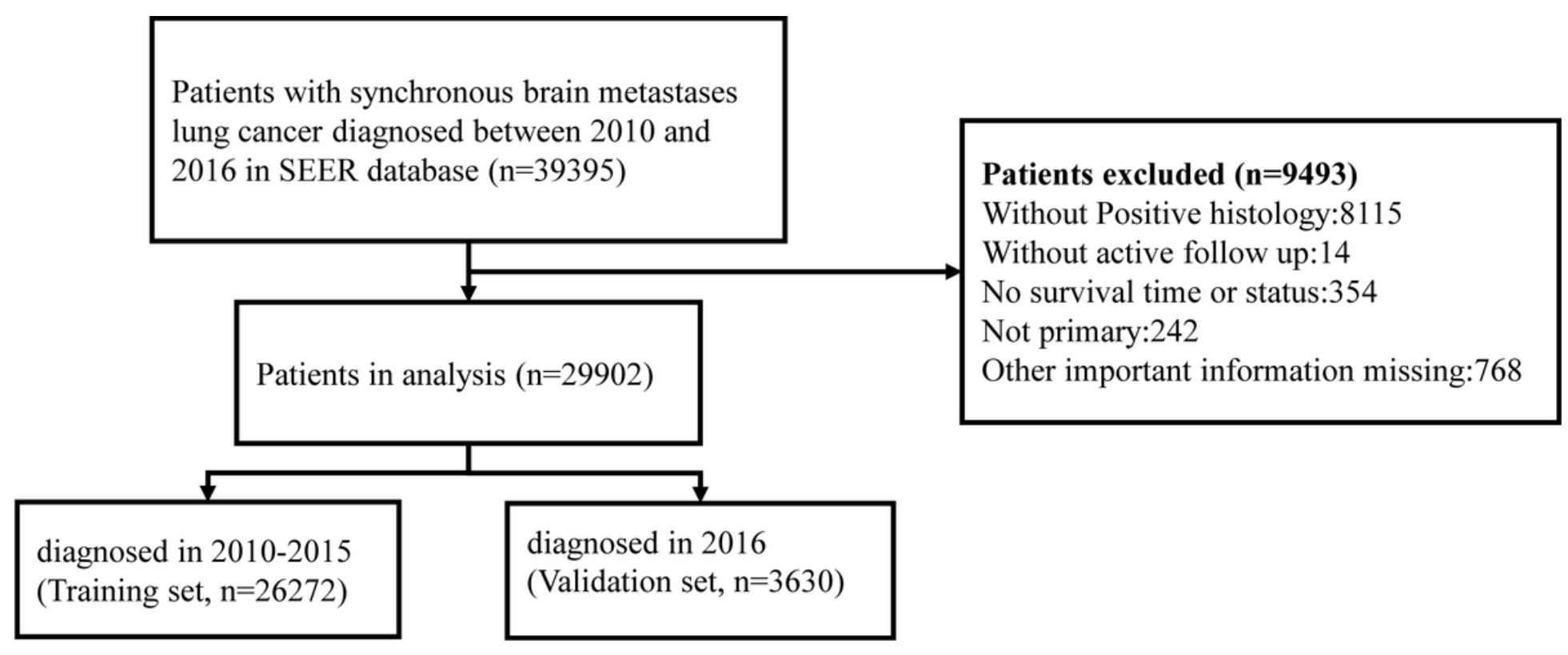

\section{Figure 1}

The flowchart of patient selection from SEER database.

A

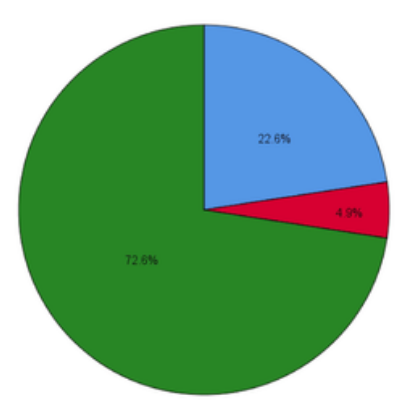

B

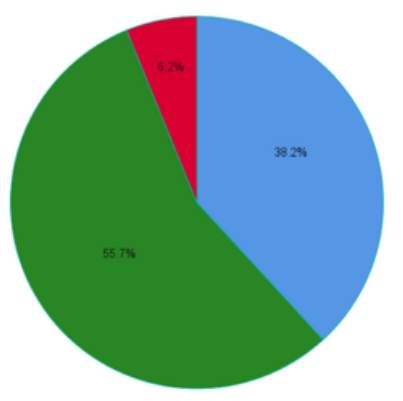

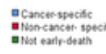

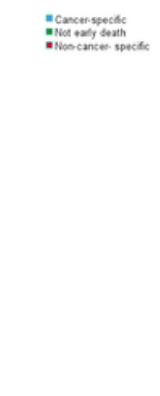

Figure 2

Distribution of the incidence of overall and cancer-specific early death in all lung cancer patients (A) and lung cancer with synchronous brain metastasis patients (B). 

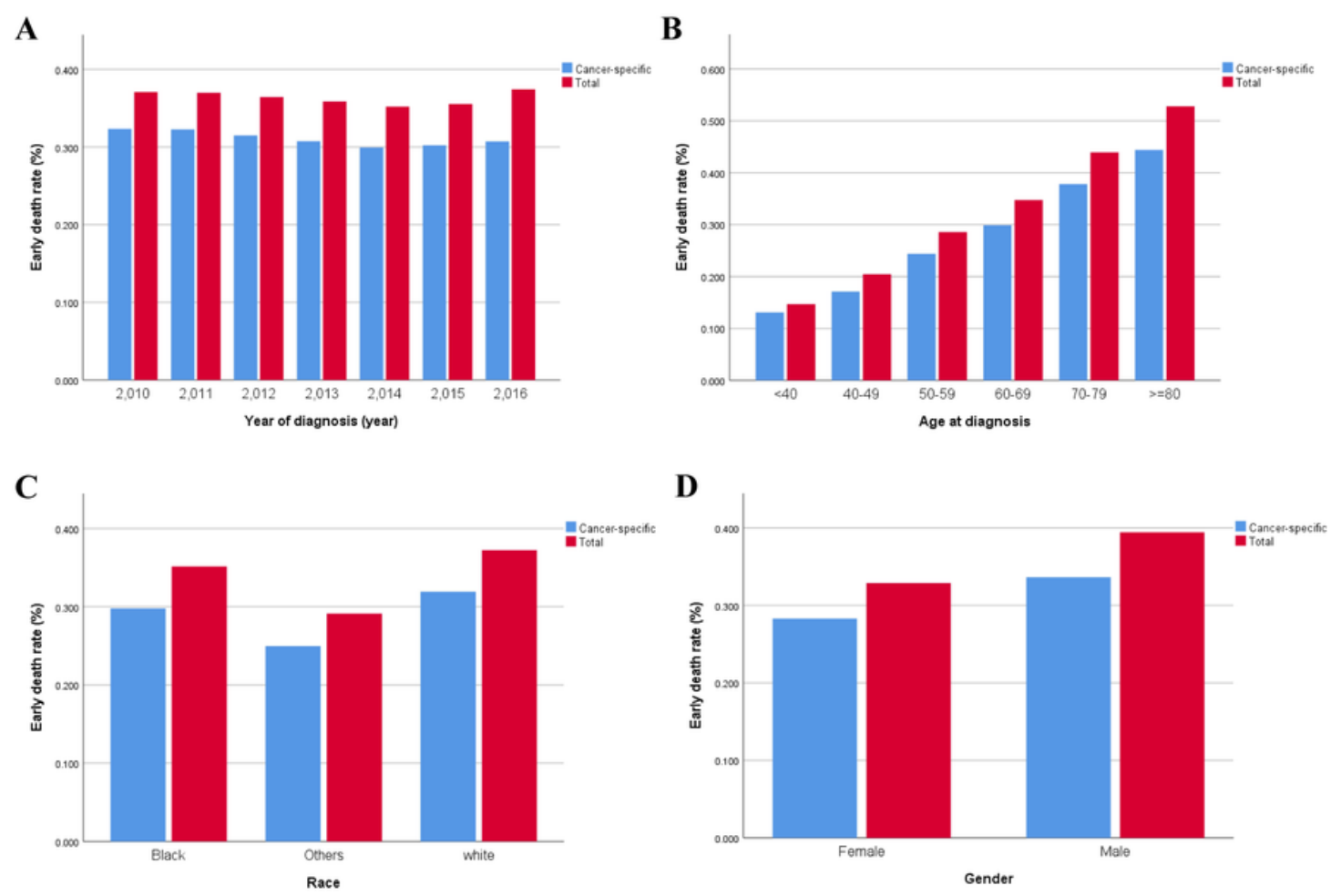

Figure 3

Rate of overall and cancer-specific early death in lung cancer with synchronous brain metastasis patients stratified by year of diagnosis (A), age at diagnosis (B), race (C) and gender (D). 
A

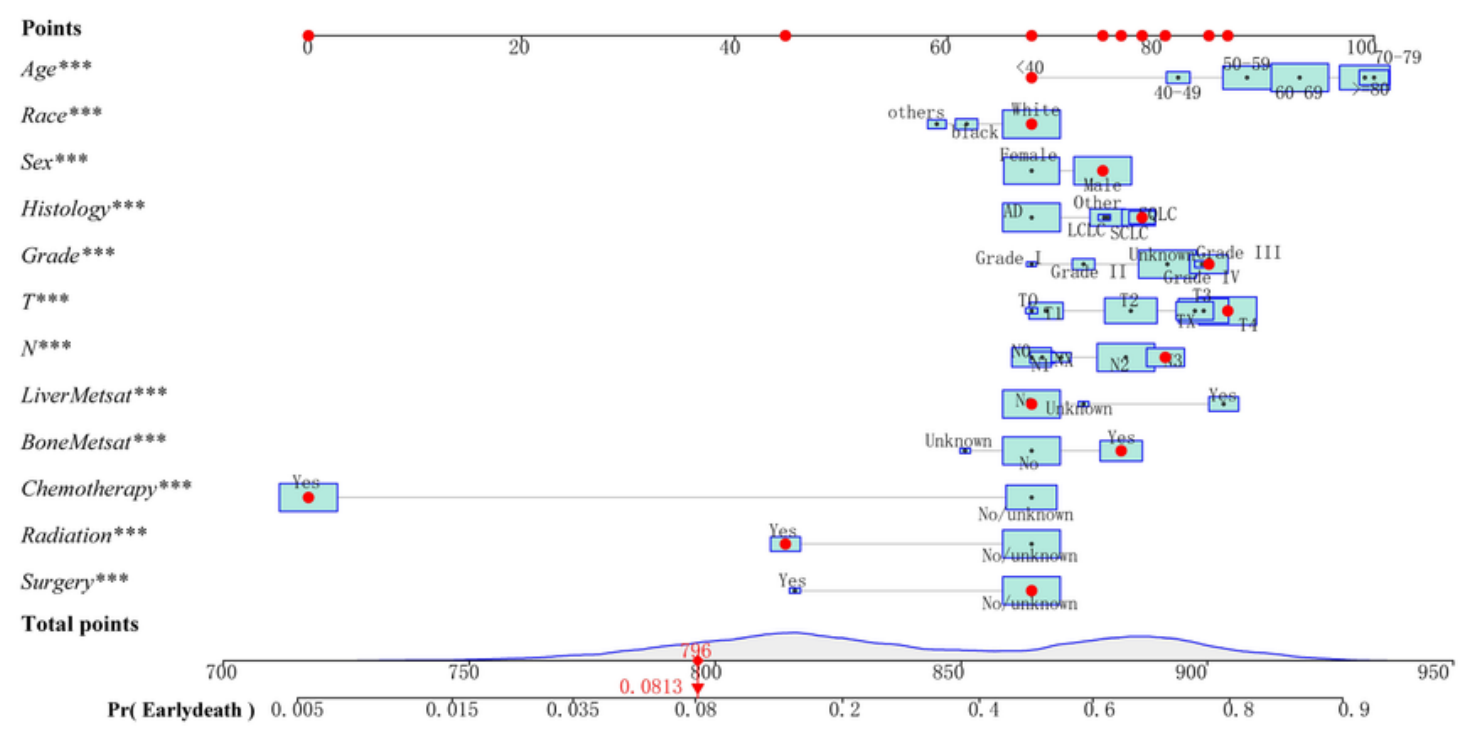

B

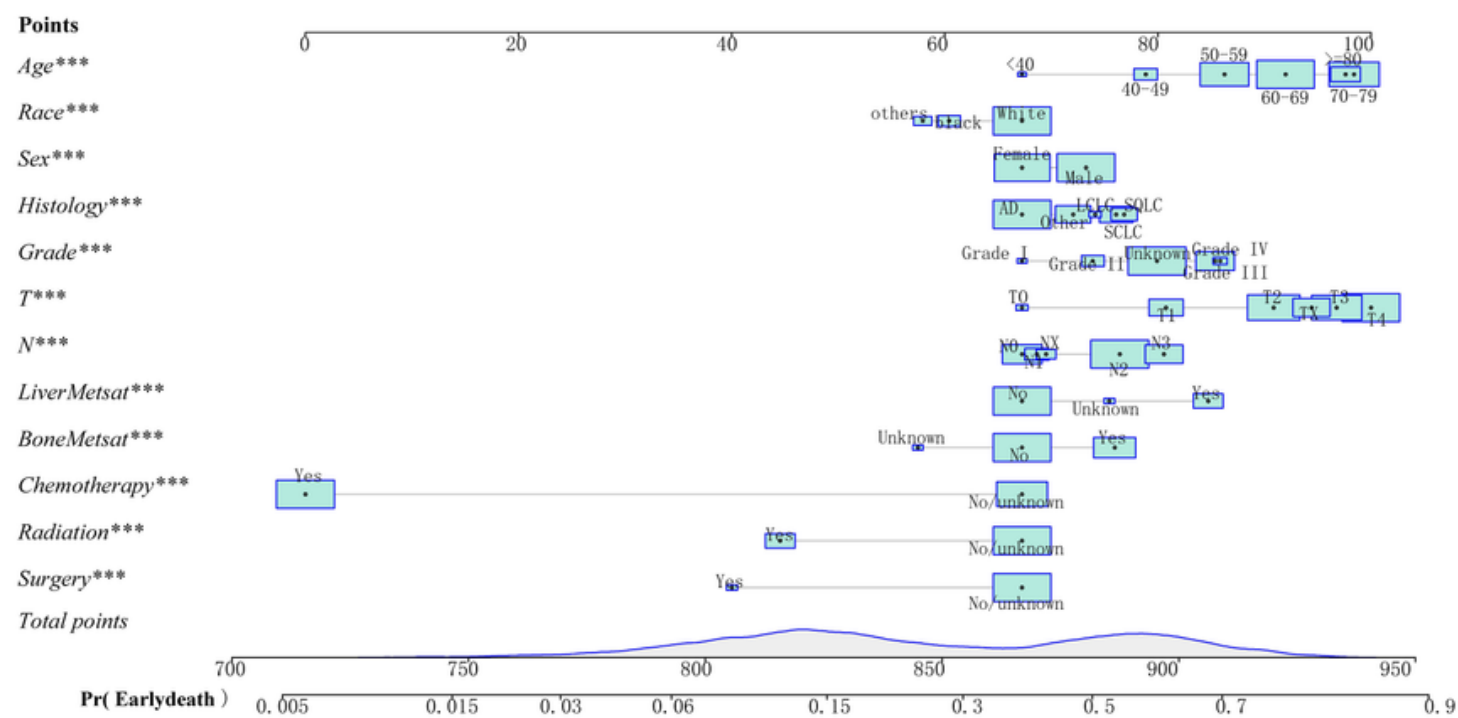

\section{Figure 4}

The predictive nomogram for the overall (A) and cancer-specific (B) early death of lung cancer with synchronous brain metastasis patients in the SEER database diagnosis between 2010 and 2015. 
A

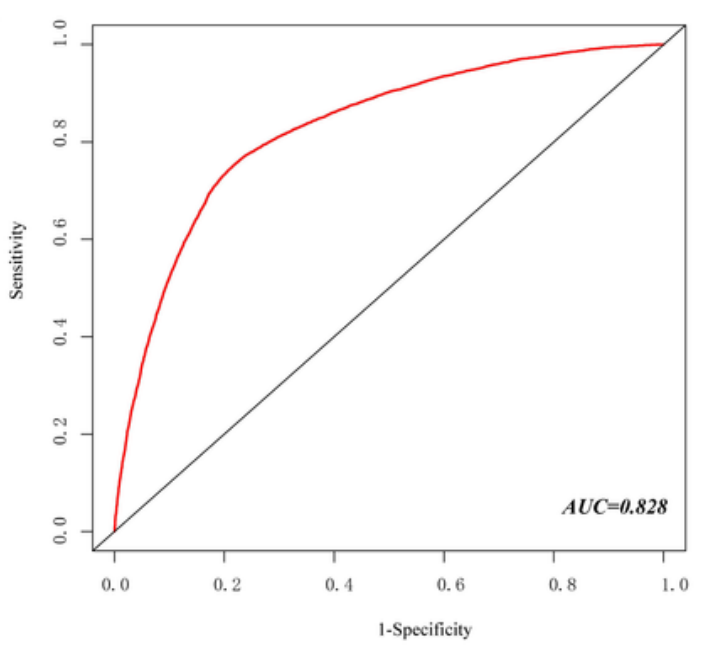

C

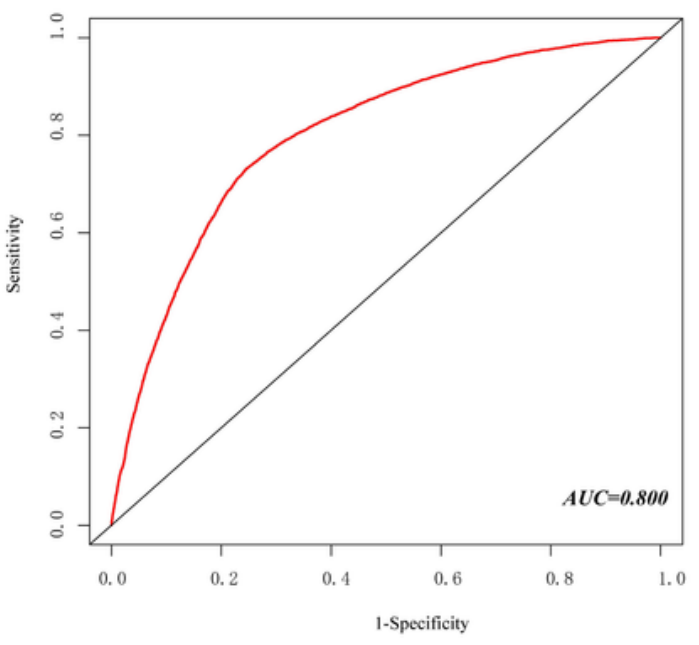

B

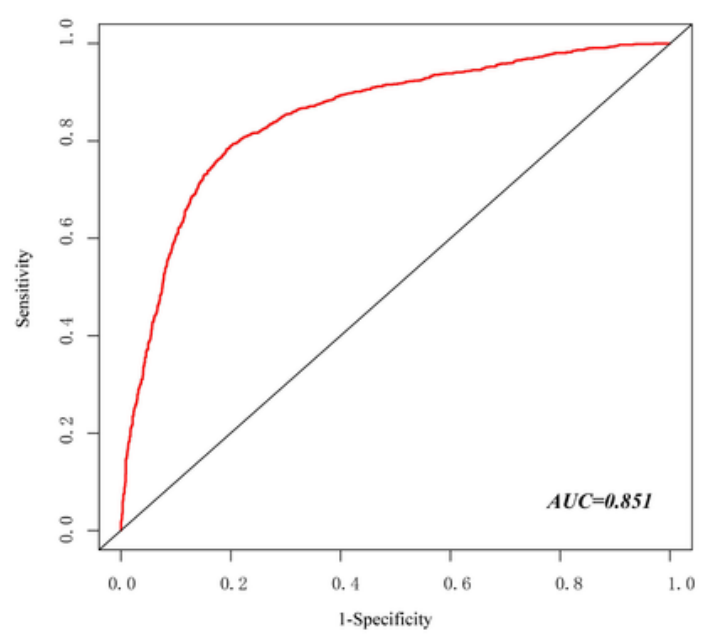

D

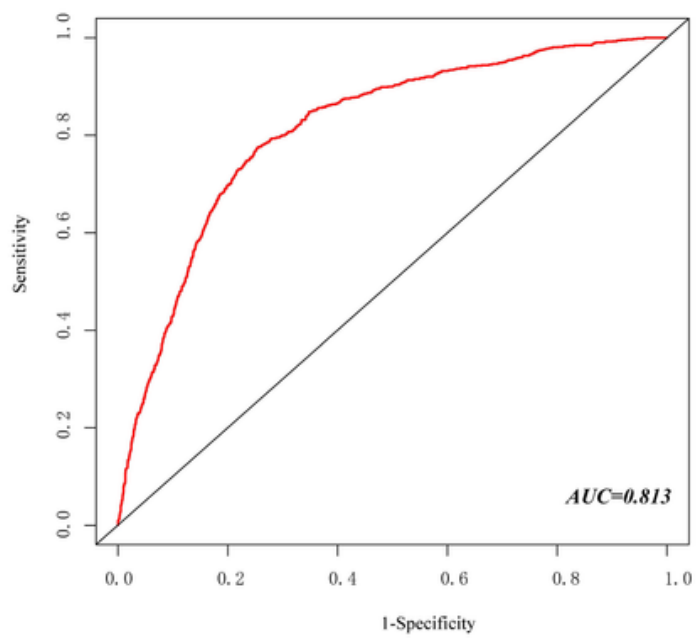

\section{Figure 5}

ROC curves for the nomogram. (A) The ROC curve for the overall early death nomogram in the SEER database diagnosis between 2010 and 2015; (B) The ROC curve for the overall early death nomogram in the SEER database diagnosis at 2016; (C) The ROC curve for the cancer-specific early death nomogram in the SEER database diagnosis between 2010 and 2015; (D) The ROC curve for the cancer-specific early death nomogram in the SEER database diagnosis at 2016; 
A

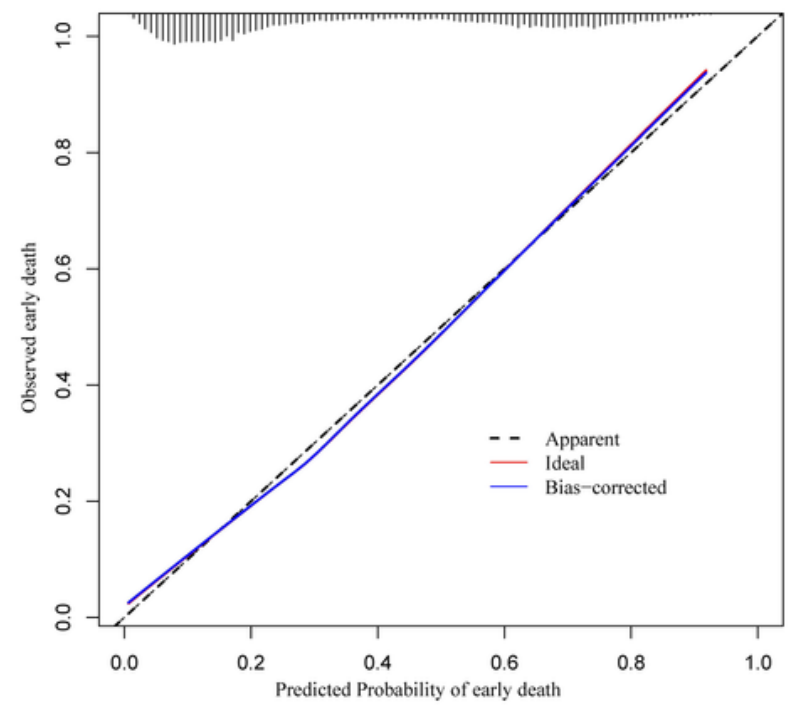

$\mathrm{C}$

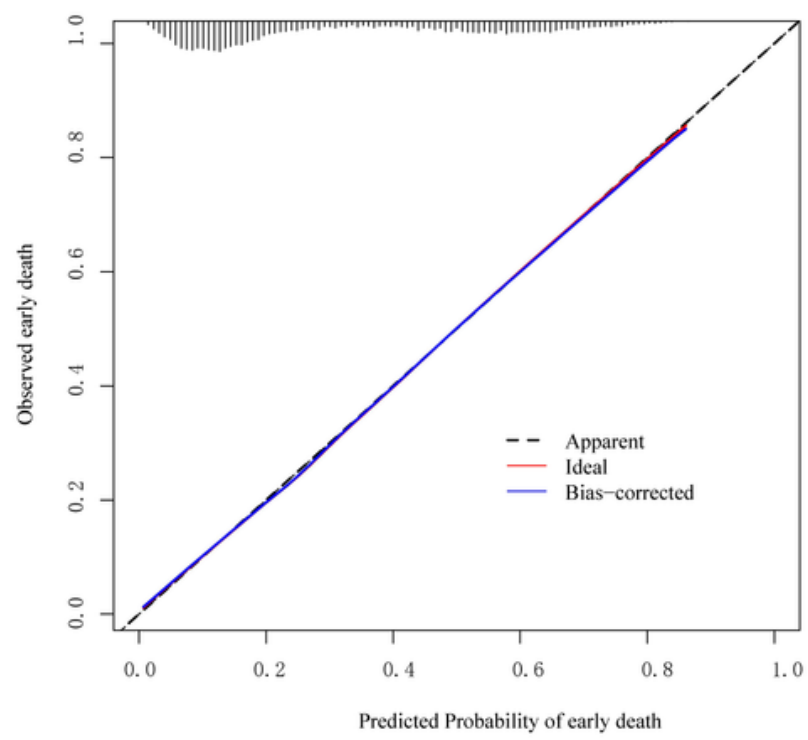

$\mathrm{B}$

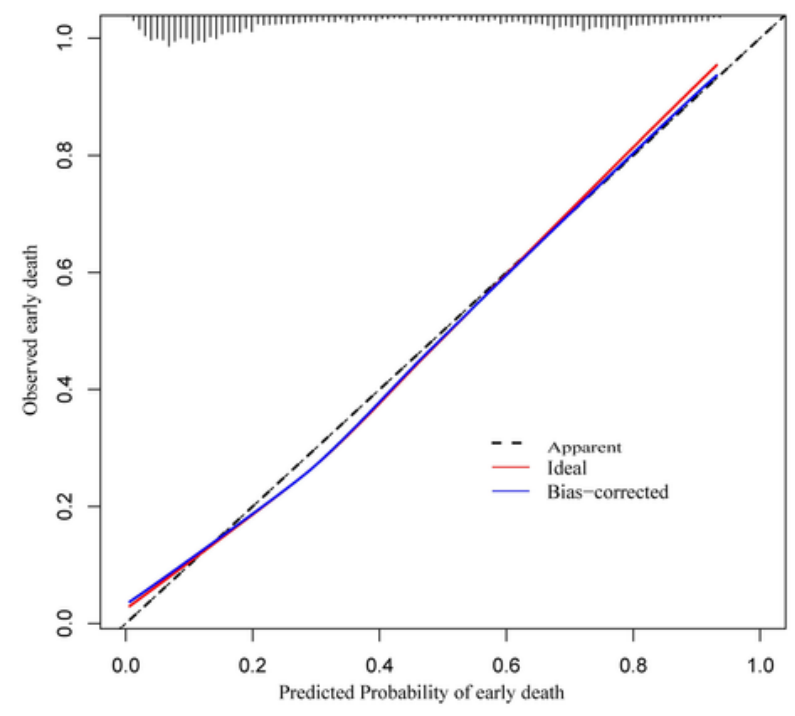

$\mathrm{D}$

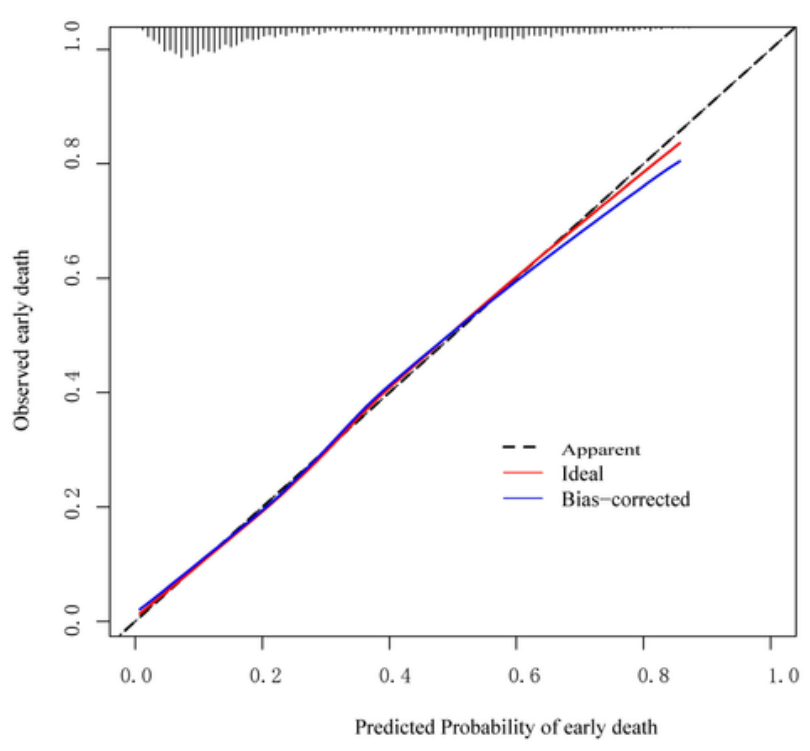

Figure 6

Calibration plots for the nomogram of $(A)$ overall early death in the SEER database diagnosis between 2010 and 2015; (B) overall early death in the SEER database diagnosis at 2016; (C) cancer-specific early death in the SEER database diagnosis between 2010 and 2015; (D) cancer-specific early death in the SEER database diagnosis at 2016; 

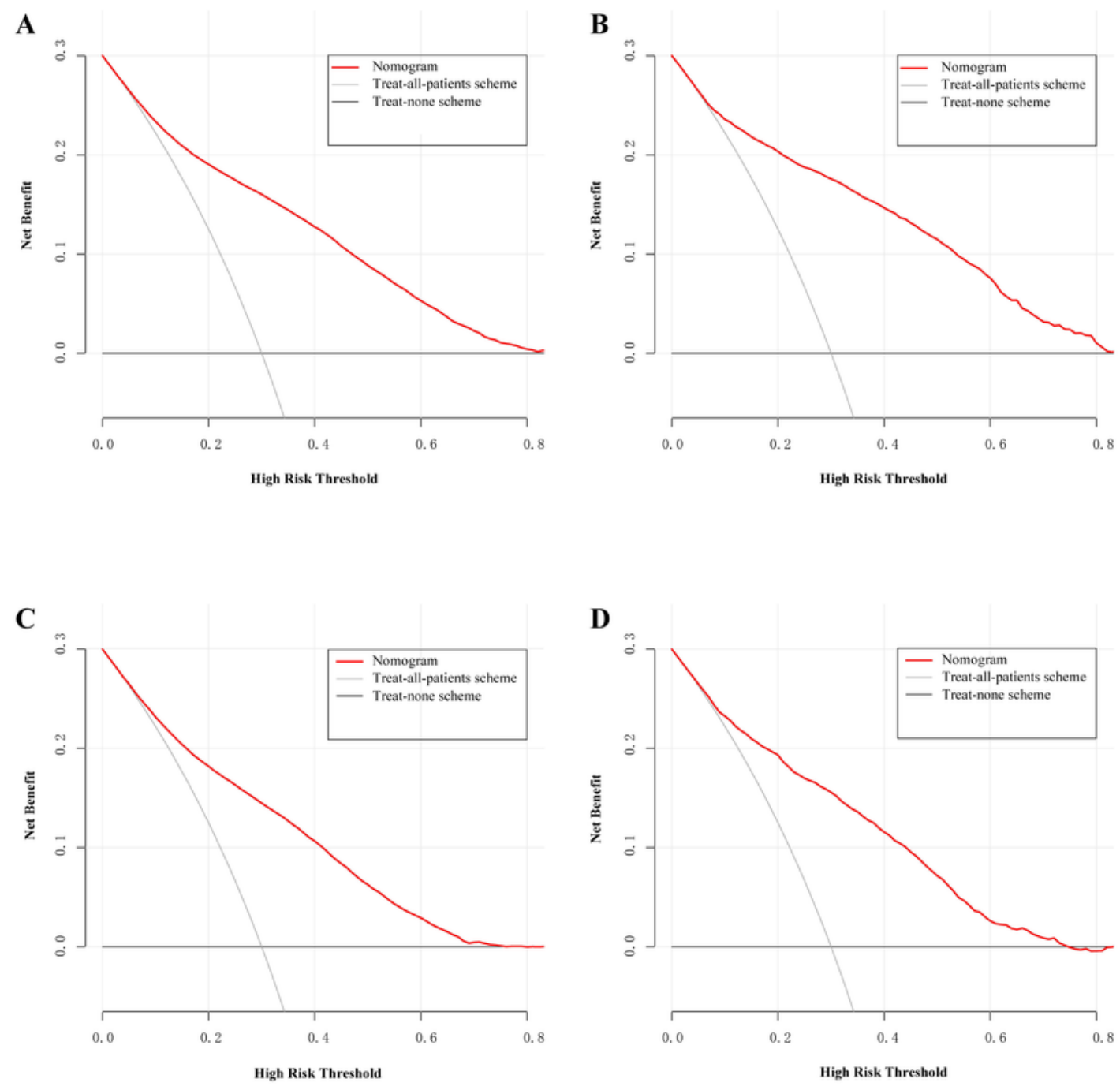

\section{Figure 7}

Decision curve analyses (DCAs) for the nomogram of (A) overall early death in the SEER database diagnosis between 2010 and 2015; (B) overall early death in the SEER database diagnosis at 2016; (C) cancer-specific early death in the SEER database diagnosis between 2010 and 2015; (D) cancer-specific early death in the SEER database diagnosis at 2016; 
A

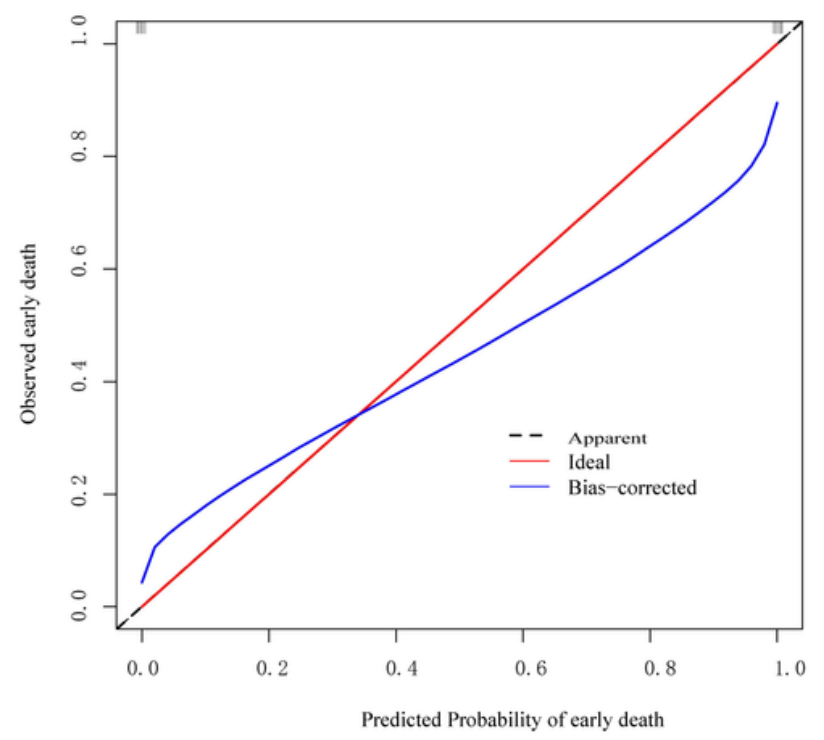

B

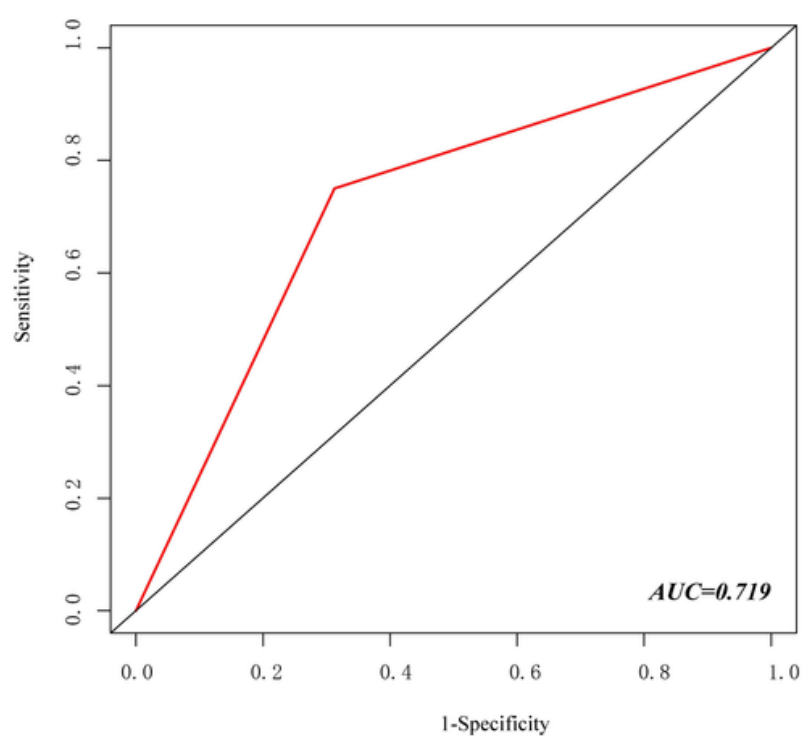

$\mathrm{C}$

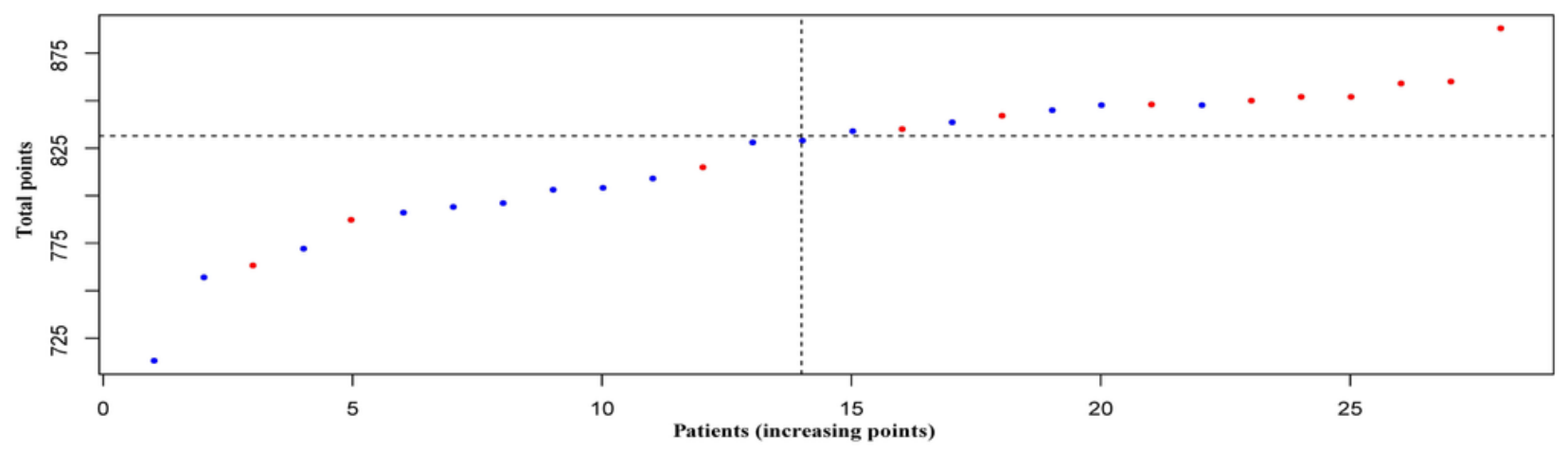

Figure 8

Validation in hospital cohort. (A) the calibration plots for the nomogram; (B) the ROC curve for the nomogram; (C) Total points distribution and early death status of patients in the hospital cohort.

\section{Supplementary Files}

This is a list of supplementary files associated with this preprint. Click to download.

- Supplementarymaterials.xlsx 